\title{
ECLECTIC APPROACH APPLIED TO DATA TRANSFORMATION CURRICULUM COURSE
}

\author{
Fernando Moreira ${ }^{1,2,3}$, Maria João Ferreira ${ }^{1,4}$, Abílio Cardoso $0^{1,2}$ \\ ${ }^{1}$ Univ Portucalense, Research on Economics, Management and Information Technologies - \\ REMIT (PORTUGAL) \\ ${ }^{2}$ Univ Portucalense, Portucalense Institute for Legal Research - IJP (PORTUGAL) \\ ${ }^{3}$ IEETA, Universidade de Aveiro (PORTUGAL) \\ ${ }^{4}$ Centro Algoritmi, Universidade do Minho (PORTUGAL)
}

\begin{abstract}
The present society, and in particular the organizations, are currently undergoing a series of metamorphoses of political, economic and social order. These metamorphoses, often referred to in the literature as digital transformation, are due to the rapid and uncontrollable evolution of information technologies and the role they can play in the organizational context. Digital Transformation (DT) is therefore a highly complex and comprehensive enterprise throughout the organization. However, digital transformation alone does not come into any organization for the much-desired success to happen; it is necessary that the information systems, the basis of operation of an organization, are aligned and are part of the same transformation. In this context, organizations have to follow technological developments, update their IS to become agile and innovative so as not to lose competitiveness. Analyzing the scenario of digital transformation, it becomes clear the need for institutions, namely higher education, to offer training to present and future workers in this area. In this paper it is proposed an extension of a curriculum of a course in Digital Transformation in order to accommodate the approach called ECLETIC that aims the use active methodologies in the teaching learning process. The use of the ECLETIC approach is justified by the fact that in addition to a curriculum of any one course must respond to current needs and trends, it should also address the way these skills are acquired, which is why the teaching-learning process is not less important.
\end{abstract}

Keywords: Information systems in organizations, digital transformation, digital transformation curriculum.

\section{INTRODUCTION}

Organizations have suffered a large (r)evolution at the social, economic and technological levels. Digital Transformation (DT) is a highly complex, organization-wide endeavour. For DT to succeed, Information Systems (IS) must be aligned with both the organization and the adoption of DT. According to [1] the concept "Digital transformation" is not new at all and it was also introduced in the late 1990s and again mentioned in the mid-2000s [2]. The same authors show that the designation can be divided into two expressions "digital" used to be synonymous with "IT", and "transformation" means that digital usages integrally enable new types of innovation and creativity in a particular domain, rather than just enhance and support traditional methods. In this context, DT affects both individual businesses and whole segments of society, such as government, mass communications, art, medicine, and science [3]. With the growing pace of technological advances and the need for more agile organizations, so as to become more competitive and innovative, new curricula that consider DT in $1^{\text {st }}$ cycle courses in computation field are required to address the needs of present and future workers in this field of knowledge. [4]

Any course of a $1^{\text {st }}$ cycle study curriculum in the computation field should provide students with skills that enable them to acknowledge and understand the importance of DT in organizations. While the scientific and organizational communities are currently mainly focused on technology and innovation, it is the moment to discuss that is the most relevant knowledge which students need to acquire in the field of digital transformation. In order to provide the necessary skills when they will work in an organizational context. Following this reflection, it was used an approach in a DT curriculum [4] that puts forward digital transformation as a central, fundamental and powerful concept.

However, it is important not only to take into account the curriculum of any course but also the learning teaching process to use. The process should take into account students currently attending higher education institutions and who are referred to as Z-Generation. 
The development of digital technologies and their application / use in the day to day over time has served as a basis for the characterization of generations. This reality is clearly evidenced in a study presented by $\mathrm{Ma}$ et al [5]. Table 1 summarizes the characteristics of the different generations. Through the table analysis it can be verified that the traditional education system does not meet the profile of the current generations, thus evidencing the need for a disruption of the education system in general, and in particular higher education, for success to occur. In addition to the above discussed, the literature also shows that a large number of students who attend higher education ends up not finishing their studies being one of the causes of demotivation. This demotivation often relates to the general education system and the teaching learning process in particular.

Table 1 - A summary of the characteristics of different generations (adapted from [5]).

\begin{tabular}{lccccc}
\hline \multicolumn{1}{c}{ Generation } & $\begin{array}{c}\text { Greatest / } \\
\text { Silient }\end{array}$ & Baby Boomers & Gen X & Millennials & Gen Z \\
\hline $\begin{array}{l}\% \text { relatively to the } \\
\text { global population } \\
\text { Communication style }\end{array}$ & $5 \%$ & $15 \%$ & $20 \%$ & $27 \%$ & $32 \%$ \\
Main technology & Car & Television & PC & Smartphone & $\begin{array}{c}\text { Virtual/ Augmented } \\
\text { reality }\end{array}$ \\
Digital proficiency & $\begin{array}{c}\text { Pre- } \\
\text { Digital }\end{array}$ & $\begin{array}{c}\text { Digital } \\
\text { Immigrants }\end{array}$ & $\begin{array}{c}\text { Early Digital } \\
\text { Adopters, }\end{array}$ & Digital Natives & Digital Innate \\
\hline
\end{tabular}

The process teaching learning more using these days still supports itself in so-called traditional teaching, i.e. the use of expository classes where the teacher is the center of the learning process [6]. But as mentioned the current context forces a disruption of the traditional process (process that reports to the 19th century), according to [7] the teaching "has now also to meet the demands and needs of a democratic and inclusive society, permeated by differences and guided by the inter, multi and transdisciplinary knowledge, with which we live in this early 21st century " [7]. In addition to what Chickering and Gamson [8] states "Learning is not a spectator sport. Students do not learn much just by sitting in class listening to teachers, memorizing prepackaged assignments, and spitting out answers. They must talk about what they are learning, write about it, relate it to past experiences, and apply it to their daily lives. They must make what they learn part of themselves" [8].

In order to respond to this recent context, evolution of technologies and digital students, different approaches appear in the literature, namely the active methodologies [13][14]. The active learning methodologies [9] [10] [11] [12] are, in turn, student-centered approaches in that they transfer to those the responsibility over the management of their learning experience. It is advised to place students often in a situation of collaboration with classmates. In an active learning situation, teachers assume the role of facilitators or mediators rather than information providers in a unidirectional way. The presentation of facts, often introduced through direct reading, is mitigated in favor of class discussion, problem solving, cooperative learning and writing exercises (classified and unclassified). Other examples of active learning techniques include role-playing, case studies, group projects, or rolereversal dynamics such as think-pair-share, peer teaching.

In this paper, the IEarning eCosystem bLendEd aCTIve teChniques (ECLECTIC) [15] will be applied to a Digital Transformation curriculum course. The proposed approach took into consideration, in addition to the motivational aspects, the fusion of several learning strategies for the development of new competences, framed in the current and future moment, in which the digital transformation predominates globally and in particular in organizations.

The paper is organized as follows. In section 2 the background of the approach on the themes of information systems and digital transformation as well as on active methodologies is presented and discussed. Section 3 describes the proposed approach, providing its rationale and depicting the main features of the proposed approach. And, finally section 4 presents the final conclusions future work. 


\section{BACKGROUND}

\subsection{Information Systems}

Nowadays as referred ISs are central on any organization [16], since they bring significant competitive advantages and strengthened market positions [17]. Regardless of its type, size, purpose or means, any organization has an IS to support its internal operations and its interactions with the external environment. IS can be defined as "Information System is organization system that can be used to integrate several functional fields of organization, such as planning, manufacturing, marketing, distribution and e-business that can be used to support some management function of an organization as well as expand the business process" [18]

Organizations face daily pressures to demonstrate their ability to adapt quickly to unpredictable changes in their dynamics in terms of technology, social, legislative, possesses improvement, competitiveness and globalization. Therefore, currently organizations have to survive and become agile against the market changes as well as to anticipate those changes by increasing their business processes [19].

Thus, to ensure their place in this difficult context, organizations must always be agile and must ensure their sustainability through continuous improvement of their IS [20]. Therefore, the agility of ISs in organizations should be considered today as one of the primary objectives of any organization [21].

According to [22], ISs have emerged in the last decades as a hopeful "tool" used for integrating and extending business processes across boundaries of business functions of an organization, at both intra and inter-organizational levels, in a worldwide economy with increasing global and competitive business operations. In this context, the development of ICT and the technological advances in ISs have provided a solution to the growing needs of information integration in the field of business, supporting the operations at global level. Moreover, ISs have progressed in a constant interaction between a permanent and random change [21].

\subsection{Digital Transformation}

The definition of digital transformation (DT) as referred is not consensual among the stakeholders involved in this issue, particularly in organizations, leading to several perspectives of what it really means. These perspectives range from a focus on technology, to digital customer engagement, to new digital business models and so on. The lack of clarity often results in piecemeal initiatives, missed opportunities and false starts in the organization digitalization.

There are several definitions of digital transformation in the literature. In 2008, Lankshear and Knobel [23] defines digital transformation as "is achieved when the digital usages which have been developed enable innovation and creativity and stimulate significant change within the professional or knowledge domain". Another interesting definition proposed by [24] that defines digital transformation as "the continuous process by which enterprises adapt to or drive disruptive changes in their customers and markets (external ecosystem) by leveraging digital competencies to create new business models, products, and services". Finally Solis defined DT as "the realignment of, or new investment in, technology, business models, and processes to drive new value for customers and employees and more effectively compete in an ever-changing digital economy" [25].

Following this line of reasoning, from the organizations' point of view, DT can be seen as a deep and accelerating transformation with regard to processes, activities, competences and models, in order to take advantage of the changes and opportunities offered by the inclusion of digital technologies into an organization. As shown in figure 1, [1] emphasizes that organization transformation is a fundamental change during which organizations reinvent themselves. 


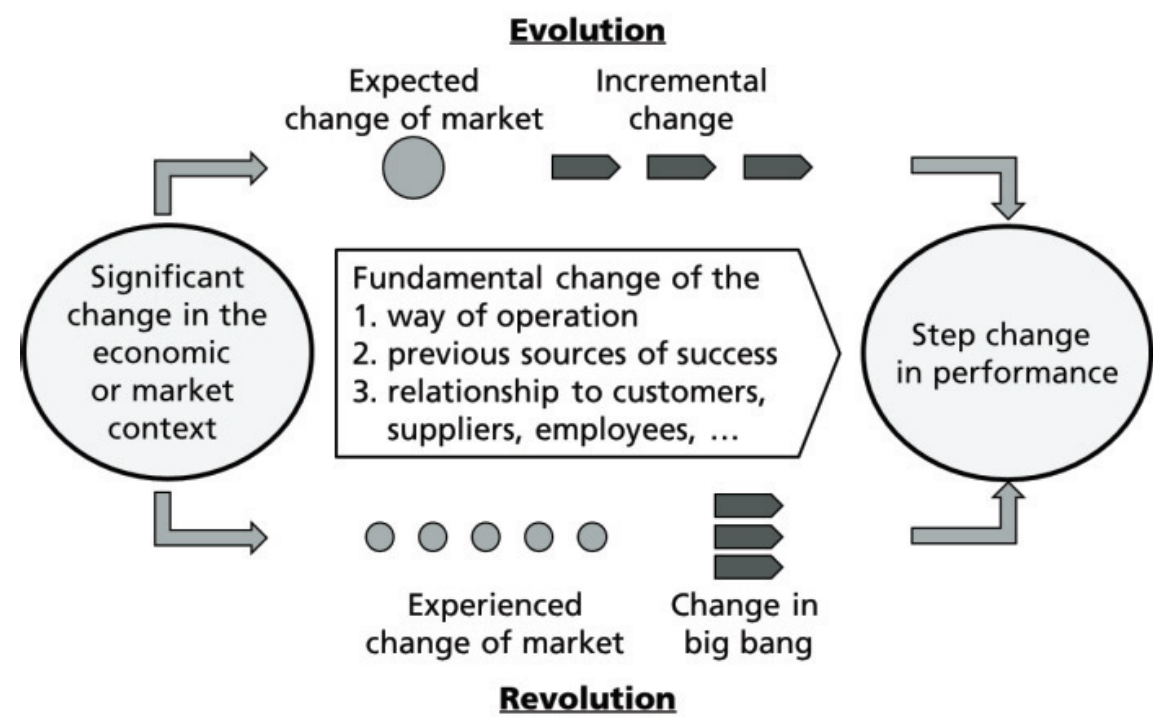

Figure 1. Process of enterprise transformation (adapted from [1]).

On the other hand, Uhl and Gollenia [26] enrich the DT concept, arguing that the adoption of technology-based change is focused on four technology enablers: (1) cloud, (2) mobile, (3) social, and (4) big data - analytics. Hence, DT draws on these four pillars to place a business context over the technologies, while taking advantage of them to support innovation. The more significant use of the pillars of DT has been driven by innovation accelerators, which include, among other solutions, loT, Robotics, 3D Printing, Artificial Intelligence, Augmented and Virtual Reality, Cognitive Systems and Next Generation (NextGen) Security [27]

\subsection{Active methodologies}

Active learning is currently considered one of the effective learning strategies as it goes to the current students profile meeting - Generation $Z$. There are several authors in the literature who define the concept of active learning, namely Vos and Graaff [28], that identify the concept of active learning as an effective teaching methodology to stimulate students to become actively involved in their own learning, to achieve complex goals, to think critically and to solve problems. Gudwin [29] state that active learning is "the technical term for a set of pedagogical practices that address the students' learning process under a different perspective from that of classical methodologies". Konopka, Adaime, and Mosele [30] defined active learning as "the process of acquiring knowledge, skills, values and attitudes by any educational strategy that involves or engages students in the process by leading them to activities and debates, instead of just putting them in the position of passively listen to the information given by the teacher." According to [31], active learning promotes a higher level of learning through the process of metacognition. In this context, Kane [32] defined a set of characteristics that characterize Active learning: 1) active engagement of students in learning, 2) students taking responsibility for their own learning, and sometimes for the learning of others, 3 ) teachers providing activities that facilitate active learning, instead of simply transferring information.

Summarily it can be stated that in an active learning classroom, students must think, create and solve problems rather than passively listen to lecture. Active learning techniques and strategies can be used to develop quick activities that punctuate lectures. They can also be used to completely fill the class time.

As referred, active learning encompass several techniques, namely the presentation of facts, often introduced through direct reading, is mitigated in favor of class discussion, problem solving, cooperative learning and writing exercises (classified and unclassified). Other examples of active learning techniques include role-playing, case studies, group projects, or role-reversal dynamics such as think-pair-share and peer teaching. In the context of the proposal approach, are highlighted three techniques (1) Group project; (2) peer review and (3) peer teaching:

- Group projects can be defined as a learning tool that encourages collaborative work [33]. Group project have been used for a long time in face-to-face classes with the aim of contributing to the improvement of students' cognitive learning. In addition, group projects provide not only 
practical experience, but allow students to practice the concepts learned, to be creative and to understand group dynamics [34].

- Peer review is defined in [35] as a teaching strategy that involves the active participation of one student in the formative assessment of another student's work. In this context, peer review allows students to experience the "collaborative process of construction and refinement of knowledge, the subjective nature of evaluation and peer review, and the role of creativity in research" [29]. The peer reviewed base format allows students to evaluate written work by other students and make suggestions for improvement. Peer review can be done in class and / or outside of class.

- According to the literature, the peer teaching method [36] is a very relevant approach given the benefits recognized at different levels. For educational institutions, peer teaching can be used, even with limited faculty resources, without compromising the quality of teaching. Studentcentered design in peer teaching activities, along with the active role of students in the learning process, helps to shift the focus from passive apprentice to active apprentice and increase student cohesion [36]. Conclusions and further work

\section{THE PROPOSED APPROACH}

\subsection{Rational}

The proposed curriculum of a Digital Transformation course at high education [4] is well structured and presents two complete components: (1) Learning outcomes and (2) Programmatic contents. This proposal clearly justifies the programmatic content - students' needs to acquire new skills in the era of digital transformation. And, also, the learning outcomes, elaborated with the support of Bloom's and SOLO's Taxonomies. However, the teaching methodology presented is somewhat simplistic and does not take into account current students who attend higher education, called the generation $\mathbf{Z}$.

There is in the literature an approximation titled ECLETIC well supported by the literature and validated in a 1st cycle course - "New Trends in ITs". In this context, it is proposed an extension to the curriculum of the Digital Transformation course in order to accommodate the ECLETIC approach that aims to use active methodologies in the learning teaching process.

\subsection{DT Curriculum and Learning outcomes}

The proposed curriculum of a Digital Transformation course programmatic contents are as follows:

1 Introduction to digital culture and society.

2 Digital transformation impact on society: education, humanities, work, economy, politics.

3 Alignment of organization information Systems with digital transformation

4 Business Models for services offered through digital platforms.

5 Transformation of organizational structure.

6 Transformation of Society and Politics.

7 Transformation of Data Security and Privacy.

The defined learning outcomes are:

1 Demonstrate knowledge of digital culture in the context of the wider digital society context.

2 Identify the main problems and challenges of the digital society (privacy, creativity, collective intelligence, etc.).

3 Identify key drivers of technology's impact on the business ecosystem.

4 Identify and use different strategies that allow the alignment of organization information Systems with digital transformation

5 Demonstrate knowledge of the digital transformation in fields such as education, humanities, work, and politics.

6 Enable students to harness the strategic business value of information technologies through large integrated enterprise system applications. 
7 Enable students to design and manage business models for services offered through digital platforms.

8 Enable students to organizationally implement and deploy different types of information systems within and across enterprises, while understanding user needs.

\subsection{Teaching learning process}

\subsubsection{ECLECTIC approach components}

Three Active Learning techniques will be used during the semester that consists of sixteen weeks. These techniques are used together in a predefined sequence (Group Project, Peer Review and Peer Teaching) for each of the group projects carried out. The accomplishment of each of the group projects is preceded by the creation of the working groups and by a short lecture where the topics assigned to the working groups are presented.

The semester is divided in blocks of four weeks, in which each block represents the application of ECLECTIC approach (Figure 2). In the first class of each block, the groups (3 elements in each group) are constituted by the teacher and the assignment of one of the programmatic topic (1). In the next phase (2), a short-lecture on each of the subjects assigned is carried out by the teacher. In phase (3) the guidelines of the Group Project technique are explored, always with the supervision of the teacher when the students are present in class. At the end of this period, students submit their work through the LMS Moodle. After this moment, the second phase of the project is started using the Peer Review technique (4), by assigning the works submitted to different groups.

The groups review the papers (using the Peer Review techniques of a scientific paper) and complete the corresponding evaluation grid. At this stage, the teacher evaluates the work and evaluates the revisions presented by the students. The revisions are sent to the authors of the works and they have to make corrections / changes suggested by their peers, after the supervision of the teacher, who analyzes and verifies the proposed changes. The groups submit the final version in the LMS Moodle. In the penultimate phase (5), teaching sessions are held by the students to the other students on the topic they worked; at this stage the technique Peer Teaching is applied. This activity is assessed through an evaluation grid indicated above. During each block a Process Control (6) is performed in order to verify how each technique that constitutes the ECLECTIC approach is being applied and meets its purpose. At the end of this session, a new block begins with the redistribution of the elements of each group, to ensure that practically all the students worked with all. At the end of the four blocks, the final versions of all papers are grouped together and presented as conference proceedings. These proceedings are the study material that students have to prepare for a final exam.

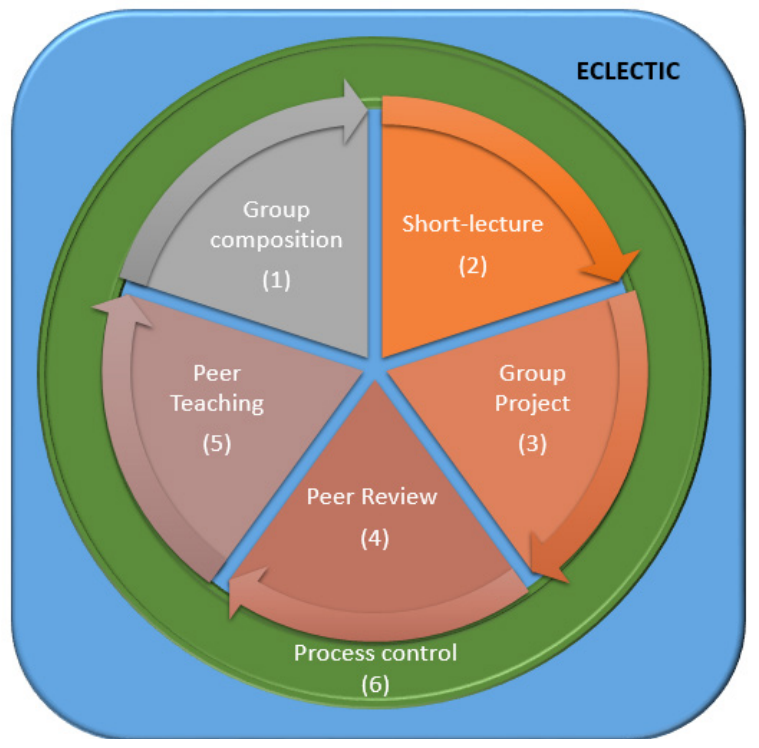

Figure 2: ECLECTIC approach. 


\subsubsection{Milestones and Assessment}

The work is monitored on the basis of Milestones $\left(\mathrm{M} \#^{n}{ }_{m}\right.$, with " $n$ " representing the project number, and the "m" milestone for delivery or evaluation of project " $n ")$. These moments are constituted by the

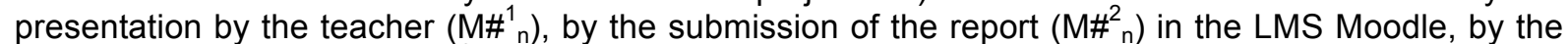
peer review of the works $\left(M \#_{n}^{3}\right)$, and by the use of the peer teaching technique $\left(M \#^{4} n\right)$ by the groups. In addition to this objective, they aim to provide students with moments of feedback allowing a dialogue between teachers and students and among students.

The pedagogical strategies used in the classroom context are the combination of the expositive and active method. The lectures (called short-lectures) aim to present the themes attributed to each working group. All students are encouraged to do reading exploration activities, consult databases, namely the use of B-on (www.b-on.pt), and feedback from the teacher, in the light of the work to be done, in the context classroom work, and / or work done outside the classroom. The active method is achieved through the use of the three active learning techniques already mentioned.

As regards the evaluation elements, these are distributed at different times and designated by milestone $\mathrm{M \#}_{4}{ }_{4}$ (with " $\mathrm{n}$ " representing project number), throughout the semester and by a final exam. The final grade of the student results from the classifications of the four projects $(60 \%$, with a weight of $15 \%$ each project) and a final exam (40\%), allowing different final classifications for each of the students. The evaluation elements of each project are as follows: Report_\#1 (50\%), Revision_of_Other_Report_group_\#2 (30\%), Presentation/Teaching_\#3 (20\%). The final exam dealt with the themes of the projects compiled and made available to students.

\section{CONCLUSIONS AND FUTURE WORK}

With digital transformation new dynamics have to be introduced in organizations. Business paradigms and their ISs are evolving and, the impact of a change in one of these items, however small, can have a negative and unforeseen effect on the desired transformation, putting many times the organization at risk. Thus, for an organization to remain credible and agile, professionals with very specific training are required. In this context, it can be verified that new ISs are required to address the needs of present and future workers in this field of knowledge.

Any course of a 1st cycle study programme in the Informatics area should provide students with skills that enable them to acknowledge and understand the importance of DT in organizations and using teaching-learning methodologies/techniques adapted to their profile, i.e. the generation Z.

While the scientific and organizational communities are currently mainly focused on technology and innovation, it is the moment to discuss what is the most relevant skills that a student needs to acquire about DT in an organizational context and how these skills should be acquired. Following this reflection, we extend the DT curriculum supported by the ECLECTIC approach that puts forward digital transformation and uses actives methodologies to support the teaching learning process.

Future work will include the validation of this approach performed under academic context.

\section{REFERENCES}

[1] M. Al-ruithe, E. Benkhelifa, K. hameed, "Key Issues for Embracing the Cloud Computing to Adopt a Digital Transformation: A study of Saudi Public Sector," Procedia Computer Science, vol. 1, pp. 1037-1043, 2018.

[2] A. Wyckoff, D. Pilat "Key Issues for Digital Transformation in the G20," 2017. https://www.oecd.org/internet/key-issues-for-digital-transformation-in-the-g20.pdf

[3] P. Vezyridis, S. Timmons, H. Wharrad, "Going paperless at the emergency department: A socio-technical study of an information system for patient tracking," Int J Med Inform., vol. 80, no. 7, pp. 455-465, 2011.

[4] F. Moreira, M.J. Ferreira, I. Seruca, "Digital Transformation a New Challenge for Higher Education: A Curriculum Proposal," In Proceedings of the 10th annual International Conference of Education, Research and Innovation (ICERI2017), vol 1, pp 8124- 8131, 2017. 
[5] B. Ma, S. Naha, F. Tran, "Future Reality: Virtual, Augmented \& Mixed Reality (VR, AR \& MR) Primer," BofA Merrill Lynch, 2016, http://www.alexboch.com/uploads/3/0/9/6/30960525/future_reality_sep_2016.pdf

[6] J. D. Walker, S. H. Cotner, P. M. Baepler, M. D. Decker, "A Delicate Balance: Integrating Active Learning into a Large Lecture Course", CBE-Life Sciences Education, vol. 7, pp. 361-367, 2008.

[7] U. F. Araújo, "The fourth educational revolution: the change of times, spaces and relations in the school from the use of technologies and social inclusion", ETD - Educação Temática Digital, vol. 12, no. 1, pp. 31-48, 2011.

[8] A. W. Chickering, Z. F. Gamson, "Seven Principles for Good Practice," AAHE Bulletin, no. 39, pp.3-7, 1987.

[9] C. C Jossey-Bass Bonwell, J. A. Eison, "Active learning: Creating excitement in the classroom", ASHE-ERIC Higher Education Rep. No. 1, Washington, DC: The George Washington University, School of Education and Human Development, 1991.

[10] B.G. Davis, "Tools for teaching", 2nd ed. San Francisco: Jossey-Bass Publishers, 2009.

[11] K.R. Wentzel, A. Wigfield, "Handbook of Motivation at School", Taylor and Francis -library, 2009.

[12] R.M. Felder, R. Brent, "Navigating the bumpy road to student centered instruction," 1996 http://www4.ncsu.edu/unity/lockers/users/f/felder/public/Papers/Resist.html

[13] R. R. Gudwin, "Aprendizagem ativa," 2015, http://faculty.dca.fee.unicamp.br/gudwin/activelearning

[14] C. L. Konopka, M. B. Adaime, P. H. Mosele, "Active teaching and learning methodologies: some considerations," Creative Education, vol. 6, no. 14, pp. 1536-1545, 2015.

[15] F. Moreira, M. J. Ferreira, A. Cardoso, A. Gomes, C. Collazos, "Learning ecosystem for higher education disruption: A new approach proposal based on blended active learning techniques," In Proceedings of the 10th annual International Conference on Education and New Learning Technologies (EDULEARN18), Vol 1, pp 0843-0853, 2018.

[16] D. Romero, F. Vernadat, "Enterprise information systems state of the art: Past, present and future trends," Computers In Industry, no. 79, pp. 3-13, 2016.

[17] A. Látečková, V. Bolek, L. Szabo, "Information Systems in Agricultural Enterprises: An Empirical Study in Slovak Republic," Agris On-Line Papers in Economics \& Informatics, vol. 10, no. 2, pp. 49-60, 2018.

[18] N. N. Annisa, D. I. Sensuse, H. Noprisson, "A systematic literature review of enterprise information systems implementation," International Conference on Information Technology Systems and Innovation (ICITSI), Bandung. pp. 291-296, 2017.

[19] C. Agostinho, Y. Ducq, G. Zacharewicz, J. Sarraipa, F. Lampathaki, R. Poler, JardimGoncalves, "Towards a sustainable interoperability in networked enterprise information systems: Trends of knowledge and model-driven technology," Computers in Industry, Elsevier, Future Perspectives On Next Generation Enterprise Information Systems, no. 79, pp.64- 76, 2016.

[20] R. Imache, S. Izza, M. Ahmed-Nacer, "Clustering-based urbanisation to improve enterprise information systems agility," Enterprise Information Systems, vol. 8, no. 9, pp. 861-877, 2015.

[21] Li Da Xu, "Enterprise Systems: State-of-the-Art and Future Trends," IEEE Tran. Ind. Inform, vol 4, no. 7, pp. 630-640, 2011.

[22] J. Nieminen "Understanding \& Managing Digital Transformation - A case study of a large Nordic retailer," 2014.

https://aaltodoc.aalto.fi/bitstream/handle/123456789/14104/master_Nieminen_Jesse_2014.pdf? sequence $=1$

[23] IDC. Digital Transformation (DX): An Opportunity and an Imperative.; 2015. https://www.idc.com/prodserv/decisionscapes/RESOURCES/ATTACHMENTS/IDC_254721_Ex ecBrief_Digital_Transformation.pdf 
[24] D. Solis, "Digital Transformation - The six stages of digital transformation,", 2017, http://www.briansolis.com/2017/01/definition-of-digital-transformation/

[25] A. Uhl, L. A. Gollenia, "Digital Enterprise Transformation: A Business-Driven Approach to Leveraging Innovative IT." USA: Routledge Taylor \& Francis Group, 2016.

[26] IDC, "Third platform," 2016, http://www.idc.com/promo/thirdplatform

[27] K. Pond, R. UI-Haq, "Learning to assess students using peer review," Studies in Educational Evaluation, vol. 23, no. 4, pp. 331-348, 1997.

[28] N.M. Trautmann, W.S. Carlsen, C. J. Eick, F. E. Gardner, L. Kenyon, H. Moscovici, J. C. Moore, M. Thompson, S. West, "Online peer review, learning science as it's practiced." Journal of College Science Teaching, vol. 32, no. 7, p. 443-447, 2003.

[29] F. J. Prins, D. Sluijsmans, P. Kirschner, J. Strijbos, "Formative peer assessment in a CSCL environment: A case study," Assessment \& Evaluation in Higher Education, vol. 40, no. 4, pp. 417-444, 2005.

[30] S. Ramaswamy, I. Harris, U. Tschirner, "Student peer teaching: An innovative approach to instruction in science and engineering education," Journal of science education and technology, vol. 10, no. 2, pp. 165-171, 2001.

[31] D.W. Johnson, G. Maruyama, R. Johnson, D. Nelson, L. Skon, "The effects of cooperative, competitive, and individualistic goal structures on achievement: A meta-analysis," Psychological Bulletin, no. 89, pp. 47-62, 1981.

[32] S. Pukdesree, "The Comparative Study of Collaborative Learning and SDLC Model to develop IT Group Projects," TEM Journal, vol. 6, no. 4, pp. 800-809, 2017.

[33] R. Ekblaw, "Contemporary Issues in Education Research", vol. 9, no. 3, pp. 121-128, 2016.

[34] K. Pond, R. Ul-Haq, "Learning to assess students using peer review," Studies in Educational Evaluation, vol. 23, no. 4, pp. 331-348, 1997.

[35] V. Tinto, "Leaving college: Rethinking the causes and cures of student attrition," Chicago: University of Chicago Press, 1987.

[36] National Survey of Student Engagement Report, 2006. http://nsse.iub.edu/NSSE_2006_Annual_Report/docs/NSSE_2006_Annual_Report.pdf 